\title{
Global Food Insecurity in University: Literature Review
}

\section{Jia Qi Cheong}

To Link this Article: http://dx.doi.org/10.6007/IJARBSS/v11-i6/10084

DOI:10.6007/IJARBSS/v11-i6/10084

Received: 05 April 2021, Revised: 07 May 2021, Accepted: 24 May 2021

Published Online: 08 June 2021

In-Text Citation: (Cheong, 2021)

To Cite this Article: Cheong, J. Q. (2021). Global Food Insecurity in University: Literature Review. International Journal of Academic Research in Business and Social Sciences, 11(6), 51-62.

\section{Copyright: () 2021 The Author(s)}

Published by Human Resource Management Academic Research Society (www.hrmars.com)

This article is published under the Creative Commons Attribution (CC BY 4.0) license. Anyone may reproduce, distribute, translate and create derivative works of this article (for both commercial and non-commercial purposes), subject to full attribution to the original publication and authors. The full terms of this license may be seen

at: http://creativecommons.org/licences/by/4.0/legalcode

\section{Vol. 11, No. 6, 2021, Pg. 51 - 62}

Full Terms \& Conditions of access and use can be found at http://hrmars.com/index.php/pages/detail/publication-ethics 


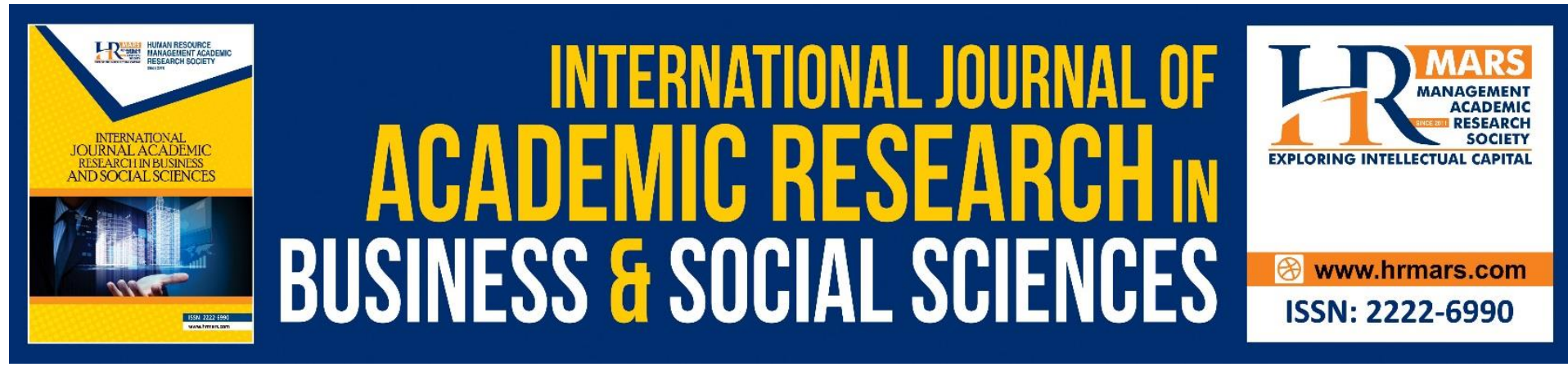

\title{
Global Food Insecurity in University: Literature Review
}

\author{
Jia Qi Cheong
}

Faculty of Business, Economics and Accountancy, Universiti Malaysia Sabah, Jalan UMS, 88400, Kota Kinabalu, Sabah, Malaysia

\begin{abstract}
Food insecurity is a global problem among universities. This article reviews the literature on food insecurity among college students globally, utilizing incidence rate of hunger, insufficient consumption and impact on educational results in university for comparison while understanding the various approach that has been taken to reveal these findings. Recommendations proposed include managing the food insecurity on-campuses, developing program in partnership with NGOs, government agencies, and faculties' members to ease its negative impact on students. Few if not no systematic literature review was ever done that study the issue of food insecurity in university globally.
\end{abstract}

Keywords: Problem, Food Insecurity, Universities, College Students

\section{Introduction}

Food insecurity is a growing public health concern with severe adverse risks on both physical and mental health among the college students and their lifestyle including productivity (Silva, Kleinert, Sheppard, et al, 2015). The USDA defined food insecurity as the inability to get adequate food and nutrition. It arises when the availability of nutritious and safe food or the capability to get adequate foods in socially acceptable manner is limited or uncertain (U.S. Department of Agriculture, 2020; Coleman-Jensen et al., 2015). There are other determinants that influence food insecurity status as well; for instance, a shortage of abilities in handling money and food (e.g. preparing financial plan, handling bills, stretching groceries at the finale of the month) (Anderson and Swanson, 2002). Based on the above, this paper conducted a systematic literature review of studies that had investigated the incident of food insecurity among college students and these includes the country of US, UK, Australia and Malaysia.

\section{Objective}

The study systematic reviews synthesize and compare the predominance of available food insecurity and associated factors among university students found globally. Due to studies on college food security published in various disciplines including nourishment and dietetics, consumer studies, and higher education, an objective analysis within a single disciple on the extent of the food insecurity problem in higher education is difficult, thus a systematic review from this study would address the challenge and present all the information from relevant studies in a comparable and order manner where meaningful analysis is uncovered by 
understanding the commonality and differences in each cases. The information from this systematic review is essential to laid out rules and planning for effective program to make certain basic needs that is crucial in food security for college students is ensured.

\section{Literature Review United States}

College students in US face major psychological, social developmental, and economic problems that could be compounded by food insecurity. The topic of food insecurity is one of rising concern among institutions of higher learning in the United States. Meza et al (2018) conducted a study to gain a deeper understanding of the processes by which food insecurity affects college student's psycho-social wellbeing and academic performance through conducting in-depth qualitative interviews with college students. The research included twenty-five undergraduate students from a major California public university who were recruited from around the campus food pantry area.

From their report, several themes related to the psychosocial effects of food insecurity were found which include the stress of food insecurity interfering with daily life, a fear of disappointing family, resentment of students in more stable food and financial situations, an inability to develop meaningful social relationships, sadness from reflecting on food insecurity, feeling hopeless or undeserving of help, and frustration directed at the academic institution for not providing enough support. Meza et al (2018) also explained that the food insecurity further impacted these students' academic performance by physical manifestations of hunger and the mental trade-off between focusing on food and concentrating on academics. These findings reveals the impact of food insecurity to college students and why it matters for higher education to address food insecurity and how universities can plan meet the basic needs of students.

The themes from the in-depth qualitative interview are consistent with human behavior based on the internalizing-externalizing behavior dimension (Meza et al., 2018). According to their report, the internalizing behavior patterns includes e.g., social withdrawal or other external indicators of sadness and depression and low self-esteem while and externalizing behavior includes eg, signs of anger or frustration such as physical aggression). Therefore, it is crucial that systemic and comprehensive solutions be developed not only to mitigate food insecurity, but also to foster holistic well-being in the higher education setting, given the effect of food insecurity on physical, mental and academic well-being.

In order to for efficient and in-depth understanding of campus-specific food insecurity results, the exchange of college food insecurity data with higher education administrators and stakeholders is important. In an effort to develop a campus-specific food insecurity reports for research in a multi-institutional food insecurity analysis, Olfert et al (2020) used the evidence-based forecast C-capture, A-assemble, S-sustain, T-timelessness (eB4CAST) method. Through such an approach each institution of higher education $(n=22)$ in the United States, had a custom report prepared with their own findings. The study found that there was no proper distribution strategy for 8 percent of participants, mainly because the participants did not know an acceptable target audience. The findings of this study are consistent with studies on distribution and implementation among minority or marginalized communities. 
Researchers also point out that university students are regarded as a vulnerable group regarding to food insecurities especially because of the high cost of attending universities.

Although the feedback was overall good, there were some suggestions for improving the eB4CAST reports from the participants. Key improvements were made in the feedback, such as putting more focus on individual data, which would increase sharing across sectors as information has to be transparent and practical for effective dissemination. In order to disseminate college food insecurity results, the eB4CAST food insecurity study are shared, with many participants recognizing its importance to be shared with administrators, faculty and staff, students, other schools, and community organizations (Olfert et al., 2020).

High incidences of food insecurity among college students were found by studies before the global pandemic of coronavirus disease-2019. Owing to factors such as unemployment and closure of campus facilities, the pandemic has undoubtedly exacerbated food insecurity among college students, and because of long-standing student issues, many students do not have access federal food assistance which necessitates the need for data (Olfert et al., 2020).

Laska et al (2020) prepared a paper analyses the federal legislation on college food insecurity, as well as pandemic-related stimulus bills and their consequences for future policies and practices. From the study, surveillance data on college food insecurity in the coming years has recently been confirmed by the National Center for Education Statistics. The authors also argue that other pressing research needs include robust longitudinal cohort studies quantifying the short- and long-term effects of food insecurity, including health, academic and economic results, as well as, perhaps more significantly, rigorous assessment of natural experiments and controlled intervention trials, in order to effectively inform policy efforts (Laska et al., 2020).

The human body consumer food for energy that, in turn, fuels daily life activities. Fortin et al (2020) discuss the dynamics of food insecurity for college students by eating habits, food aid, and fitness for university students that suffers from food insecurity in the US. The findings of the study revealed that seven percent are currently enrolled in food assistance programming, and 30 percent registered are experiencing greater family enrollment. Nutritional behaviors, dietary adaptations, wellness and well-being effects, and additional campus programs addressing food assistance have been illustrated in seven main themes. A complexity diagram with the key categories of student features of food insecurity, campus resource obstacles, additional student needs, health and well-being impacts, and student adaptations and coping affected the complexity of student food insecurity was captured by data triangulation. It was found that food insecurity among college students is multifaceted and dynamic. Among individual-level variables and university systems, common patterns developed, offering a deeper understanding of both the complexity and contributors to the experience of college students. To explore this phenomenon and address student needs, more study and intervention was recommended.

Studies also shows that food insecurity is higher in US colleges and universities than in US families, rendering this a new priority for public health. A systematic study of food insecurity among US students attending higher education institutions was conducted by 
Nazmi (2018). The paper found that food insecurity was at least three times higher among students in US higher education institutions than that observed in nationally representative households. It has been shown that college students are not safe from food insecurity; on the contrary, relative to community dwelling populations, they may be at substantially higher risk.

The researchers also emphasized the importance of providing an additional measure to determine the timing of food insecurity, such as whether food insecurity was faced by students during the academic year or during seasonal breaks. Furthermore, it is critical to know if, at the end of a term, students encounter food insecurity after financial aid funds have been depleted. Although it will take time for national efforts to grow, empirical research from future studies will support federal policies that generate greater opportunities for college students to access social safety net services that would otherwise qualify for many lowincome college students by income if they were not enrolled in college (Nazmi, 2018).

Nazmi, (2018) added that the fastest way to respond to college food insecurity has been by campus food pantries. The College and University Food Bank Partnership have grown into what initially began as a handful of programs on multiple campuses, and as of March 2017, there were 400 higher education institutions (cufba.org). This partnership is a crisis response that has largely gone unaddressed. Some on-campus emergency response services help urgent emergencies, with more innovative initiatives focusing on food recovery programs that distribute food that would otherwise be lost, sharing programs for dining plans, cooking lessons, and community gardens or farms on campus. Upstream methods are important for minimizing and eliminating food insecurity in higher education. Trials on the impacts on student outcomes of food assistance or related services are imperative, as are natural studies after introduction of campus or system-wide policies. Implementation of sound policies on campus can achieve faster results in enhancing food security compared to policies at state or federal levels due to relatively fixed and controllable environments.

Caught between jobs, debt, and rising prices, many students struggles to afford basic needs, finding themselves unable to get sufficient food and adequate nutrition. In order to characterize the prevalence and dimensions of student food insecurity and associations with academic performance, Weaver et al (2019) conducted an online survey that was distributed to undergraduates at a mid-sized New Jersey Public University to assess food insecurities using the USDA food security index. The association between food insecurity and academic performance is clear and persistent, according to the study. The odds of food insecure falling into the lowest 10 percent of GPA are two times those of food safe counterparts after adjusting for other variables. A growing number of universities, and those that should not consider doing so, make available food pantries for students.

A research by Xu et al (2016) examined the perceptions of stigma resulting from food insecurity faced by residents in inner-city community which is also described as food desert in Lansing, Michigan. Sixty residents of the inner city were asked about their difficulties supplying their families with nutritious food. Four forms of structural barriers were found in the analysis that contributed to the experience of stigma. One surprising finding from this study is that women is perceived to experience more stigma in general relative to men, while men perceived more stigma only in terms of health than women. In addition, across all stigma dimensions, White residents scored higher than non-White minorities. 
As higher education institutions become increasingly aware of the problem of food insecurity within their student populations in the United States, an increasing number of institutions have taken steps to set up food banks to fight students (College and University Food Bank Alliance, 2015). A cross-campus collaboration was examined by Waity et al (2020) to evaluate levels of student food insecurity, identify factors contributing to an increased risk of food insecurity, and determine how to address food insecurity of 13 institutions in the United States. It is suggested from the study that institutions in their effort to improve student success may also consider improving access to student food which will give the same result. The authors provide a concrete example of how one school, as well as a faith-based group and a non-profit organization outside the university, partnered with several university organizations to open a food pantry to fix some of the food insecurity problems previously mentioned.

Food insecurity is a precursor of wider material and economic insecurities faced by students in college, which make it important to understand the insecurity of basic needs among college students. Regan (2019) reviews the perception of food insecurity from a sociological perspective based on economic insecurity and material hardship among college students in the United States by reviewing previous studies in the country. The analysis focuses in detail on the scope and depth of research among college students on food insecurity, discussing how food insecurity is assessed, the various methodologies of researchers to quantify it, and areas of interest. From the study, it was found that food insecurity varies by form of institution, demographic characteristics, and its health and academic outcomes associations. The review also states that there is significant space for future study in this area, from continued discussion of socio demographic patterns in student food insecurity that more deliberately includes non-traditional students and students with children, as well as working to quantify food insecurity among students at different points in time using varied reference points.

For students who attend an urban university, Silva et al (2015) examined the food and housing disadvantages that could be obstacles to academic performance. The results of the survey showed that some degree of food insecurity had been encountered by almost a quarter of the students. This research founds that experiencing food and housing insecurity has a detrimental effect on the academic success, attendance, and class completion of students. This survey despite slight limitations allowed a better understand of the housing and food needs of the diverse and urban student population.

Colleges and universities may intervene by recognizing students who face housing and food barriers, potentially increasing retention, persistence, social, and emotional results for this disadvantaged student population. In the sense of an applied, service learning opportunity, the relationship between U-ACCESS and UMass Boston has enabled doctoral students who concentrate on equal access to education to improve research skills (Silva et al, 2015). In the report, the value of collaborations within the college campus and with the surrounding community was also highlighted.

Owens (2020) assesses the prevalence and determinants of food insecurity during the COVID-19 pandemic among university students in the United States. Using a multi-step approach to food security assessment, about one in three college students faced food 
insecurity during the last 30 days, the authors found. Although food insecurity in non-student US households since the COVID-19 pandemic has risen to a similar degree, it is worth noting that many college students do not qualify for many federal and state safety net services (expanded SNAP benefits and federal stimulus). As a result, and without immediate help, college students could be disproportionately affected by food insecurity. From the report, as a direct result of the COVID-19 pandemic, the two strongest predictors of food insecurity in college students were shifts in living arrangements or lack of jobs. In order to alleviate food insecurity among college students during the COVID-19 pandemic in the United States, a strong, detailed policy response is therefore required.

National demands for alleviation and prevention policies have been prompted by reports of college students experiencing food insecurity, described as insufficient access, affordability, adequacy and stability of food. Nikolaus et al (2019) prepared a paper with analysis based on a rigorous research methodology to establish a weighted estimated prevalence of food insecurity among US students. In addition, research features that may be related to the high variability in the prevalence of recorded food insecurity were analyzed. Food insecurity experiences were reported by an estimated $41 \%$ of US college students. However, with differing measurement protocols, including the survey type and reference duration, this prevalence was drastically different. In the community, food insecurity is obviously a concern and could have a negative effect on the nutrition and academic performance of students. Testing strategies and programs to reduce food insecurity, including those already implemented, as well as future improvements, would be useful once survey methods have been enhanced.

\section{United Kingdom}

By drawing on survey data and case studies, Purdam et al (2015) analyzed the debate on food aid and the demonization of those living in poverty, the extent of hunger, and the experiences of food bank users in the United Kingdom. The case highlighted the wide number of people who use food banks, including families, the elderly and the workforce. The food aid survey indicates that food poverty is more severe when assessed in terms of food aid providers than would be indicated by an estimation based on the number of people registered using Trussell Trust-supported food banks.

An empirical study was drawn up by Lambie-Mumford (2018) to argue that the growth and popularity of food banks is the embodiment of a larger political-economic trend of social policy change that has dramatically accelerated since 2010 and included reinterpretations of the causes and responses to poverty. It illustrates the capacity of food banks as a lens for challenging the ramifications of these policy changes in relation to the significance of systemic determinants, the inadequacy of relying on ad hoc privatized welfare programs, and the growing incorporation of food banks into local welfare landscapes. According to LambieMumford (2018), the process of involving state practitioners in referring or signing individuals for assistance to food banks raises the issue of how often food bank vouchers are becoming a regular feature of UK social security and social care administration.

\section{Australia}

Whatnall et al (2019) examines the level of food insecurity among a sample of Australian university students and determines which food insecurity is predicted by socio-demographic 
and student features. From the analysis, forty-eight percent of participants were found to be food insecure. Compared to their parents' home, and undergraduate compared to postgraduate students, the odds of food insecurity were greater among students living in rental accommodation.

\section{Malaysia}

In a study by Bakar et al (2019), an important association was found between food security status with financial availability, time constraint, scholarship, academic program and parent income (2019) among university students in Pahang, Malaysia. According to the report, one of the students of the Allied Health Sciences programs, which also had the highest number of food deprived students, was the largest proportion of beneficiaries of PTPTN loans. In comparison, medical faculty students, most of whom were JPA scholarship recipients, were at the lowest level of food insecurity because they earned more support than students from PTPTN. In addition, students also had no access to adequate campus food storage and preparation facilities to prepare their own meals, which could have helped minimize their food costs. The circumstances make it difficult for them to overcome the situation for all major food security components, namely accessibility, availability including the use of food. Tackling food insecurity should therefore be one of the priorities for university administrators and relevant policy makers.

\section{Methodology}

Article for analysis in this study were gathered from journals for the period between 2015 and 2020. The methodology used for this paper consists of library search and evaluate previous literature review on the subject food insecurity in University. The systematic literature review methodology consists of three distinct steps: (1) selection of journals, (2) development of key categories and analysis framework and (3) selection of articles (Tranfield et al., 2003). To collect paper or full text review for every publication that used the terms Food security or Food Insecurity or Hunger or Food insufficient in the title, abstract or keywords. According to Liu and Liao (2017), Cheng et al, (2018); Marti-Parreno at el., 2016; Guerreiro et al, 2016), this approach of querying a database by a topic or phase is a common approach in studies that use text mining to study a body of scientific literature. References searches are based on online database such as Web of Science, Scopus, Science Direct and Google scholar. References are only taken from article journal, and full text documents and review.

\section{Policy}

According to the Laska et al (2020), members of the Society for Nutrition Education and Behavior will play a critical role in evaluating these re-opening policies to ensure that they are most responsive to the needs of food insecure students. Overall, nutrition practitioners are instrumental in the development of programs that better serve students in their pursuit of higher education and better health through collective action, good communication, and wellinformed decision-making. College food insecurity would likely only intensify without collective and timely action for policy reform.

For students, food pantries serve as a stop-gap solution when funds run painfully low. Weaver et al (2019) have stressed that stigma reduction programs should accompany food pantry services, as learners often express reluctance to use them, fearing shame and deprivation of status some associate with dependence on others. 
The main policy debate emerging from the research concerns the role of the state, the voluntary sector and business organizations in combating hunger and food poverty in the United Kingdom and the role that people should play in ensuring their own well-being. Although some funding has been provided by local authorities, food aid is largely dependent on volunteers, donations and sponsorship from supermarkets and food producers. In the UK, it can be questioned why food insecurity levels are so high and if, given the effect on people's health and well-being; the present policy strategy is economically and politically successful (Purdam et al., 2015).

The study also noted that UK social policy has traditionally not engaged much with explicit food and access issues. Social policy researchers should, therefore, think more about food issues. Food charity and food insecurity can provide an important place for exploring (in) justice issues and studying the impacts on the lives of people of changing social policy. A closer examination of the relationship between state-provided income (social security) and services (community services) in the capacity of individuals to live well can also be facilitated (LambieMumford, 2018).

Whatnal et al (2019) suggested that food pantries or food vouchers in Australia were probably the most commonly used approach to help students facing food insecurity, interventions that offer short-term relief, and there is a need for initiatives that can provide long-standing benefits and understand that being food healthy is a basic human right. In addition, policies are required to ensure sufficient support for students for factors such as accommodation and healthcare, which could apply to others such as government outside universities' obligation. In addition, future research is required among university students to examine the changes in, and effects of, food insecurity over time.

\section{Conclusion}

Food insecurity can have a grave negative impact on college student - academic performance, economic result, health and financial availability. Whereas, extra study is required to sufficiently comprehend the occupied rule of food insecurity among college students in global, it is pure that it is a problem that require attention. Recent replies are diverse and frequently comprise companies with external nonprofit and governmental agencies. In doing so, there is possible to be both proactive and reactive to student food insecurity, employed to fill differentials in the security net for students, and providing lower opportunity students to be affected by negative impact. Food insecurity among college students is a significant public health concern that might have implications for academic performance, economic result, health and financial availability. Universities that measure food insecurity among their students will be better to be found to supporter for policy alters at national and federal levels concerning college affordability and student financial assistance.

\section{Limitations}

Similar to any part of investigation, this review paper has limitations, which are to be acknowledged. First, the findings of any review were collected from the full text review online database for instance Web of Science, Scopus, Science Direct and Google scholar, and therefore literature related to food security that is absent from these database will be missing for our analysis. This data set was collected from the online database such as Web of Science, Scopus, Science Direct and Google scholar and as a result literature related to food security 
that is absent from these will be missing from our analysis. It is likely that some essential full papers are missing from our analysis, specifically in the early literature, and extra possible that the text of a paper is not representative of the whole text of a publication. Finally, our analysis is based only on papers that mention food security, and our results must be construed in this light. Consequently, research relevant to food production, markets and trade, or human nutrition that does not use the phases "food security" or "food insecurity" is missing from our analysis.

\section{Acknowledgement}

This paper was created within the project Research Grant under Skim Pensyarah Lantikan Baru (SPLB). Project registration number SLB 2001.

\section{References}

Anderson, K., \& Swanson, J. (2002). Rural Families - Welfare Reform \& Food Stamps. Policy Brief. Ithaca, New York: Cornell University.

Bakar, W. A. M. A., Ismail, S., Sidek, S., \& Abdul Rahman, R. (2019). Prevalence and factors affecting food insecurity among university students in Pahang, Malaysia. Malaysian Journal of Nutrition, 25(1), 59-67. https://doi.org/10.31246/mjn-2018-0139

Cheng, M., Edwards, D., Darcy, S., \& Redfern, K. (2016). A Tri-Method Approach to a Review of Adventure Tourism Literature: Bibliometric Analysis, Content Analysis, and a Quantitative Systematic Literature Review. Journal of Hospitality \& Tourism Research, 42(6), 997-1020. https://doi.org/10.1177/1096348016640588

Cochrane, L. (2017). Stages of food security: A co-produced mixed-methods methodology. Progress in Development Studies, 17(4), 291-306. https://doi.org/10.1177/1464993417716358

Coleman-Jensen, A., Rabbitt, M. P., Gregory CA, C. A., \& Singh, A. (2016). Household Food Security in the United States in 2015. Retrieved from https://www.ers.usda.gov/webdocs/publications/79761/err215_summary.pdf?v=426 36

Fortin, K., Harvey, S., \& White, S. (2020). Hidden Hunger: Understanding the Complexity of Food Insecurity Among College Students. Journal of the American College of Nutrition, 40(3), 242-252. https://doi.org/10.1080/07315724.2020.1754304

Gallegos, D., \& Chilton, M. (2019). Re-Evaluating Expertise: Principles for Food and Nutrition Security Research, Advocacy and Solutions in High-Income Countries. International Journal of Environmental Research and Public Health, 16(4), 561. https://doi.org/10.3390/ijerph16040561

Lambie-Mumford, H. (2018). The growth of food banks in Britain and what they mean for social policy. Critical Social Policy, 39(1), 3-22. https://doi.org/10.1177/0261018318765855

Laska, M. N., Fleischhacker, S., Petsoulis, C., Bruening, M., \& Stebleton, M. J. (2020). Addressing College Food Insecurity: An Assessment of Federal Legislation Before and During Coronavirus Disease-2019. Journal of Nutrition Education and Behavior, 52(10), 982-987. https://doi.org/10.1016/j.jneb.2020.07.001

Liu, W., \& Liao, H. (2016). A Bibliometric Analysis of Fuzzy Decision Research During 19702015. International Journal of Fuzzy Systems, 19(1), 1-14. https://doi.org/10.1007/s40815-016-0272-z 
Martí-Parreño, J., Méndez-Ibáñez, E., \& Alonso-Arroyo, A. (2016). The use of gamification in education: a bibliometric and text mining analysis. Journal of Computer Assisted Learning, 32(6), 663-676. https://doi.org/10.1111/jcal.12161

Meza, A., Altman, E., Martinez, S., \& Leung, C. W. (2019). “It's a Feeling That One Is Not Worth Food": A Qualitative Study Exploring the Psychosocial Experience and Academic Consequences of Food Insecurity Among College Students. Journal of the Academy of Nutrition and Dietetics, 119(10), 1713-1721.e1. https://doi.org/10.1016/j.jand.2018.09.006

Nazmi, A., Martinez, S., Byrd, A., Robinson, D., Bianco, S., Maguire, J., . . . Ritchie, L. (2018). A systematic review of food insecurity among US students in higher education. Journal of Hunger \& Environmental Nutrition, 14(5), 725-740. https://doi.org/10.1080/19320248.2018.1484316

Nikolaus, C. J., An, R., Ellison, B., \& Nickols-Richardson, S. M. (2019). Food Insecurity among College Students in the United States: A Scoping Review. Advances in Nutrition, 11(2), 327-348. https://doi.org/10.1093/advances/nmz111

Olfert, M. D., Hagedorn, R. L., Walker, A. E., \& Wattick, R. A. (2020). Rapid Dissemination of College Food Insecurity Findings in A Multi-Institutional Study Using the eB4CAST Approach. Nutrients, 12(6), 1646. https://doi.org/10.3390/nu12061646

Owens, M. R., Brito-Silva, F., Kirkland, T., Moore, C. E., Davis, K. E., Patterson, M. A., . . Tucker, W. J. (2020). Prevalence and Social Determinants of Food Insecurity among College Students during the COVID-19 Pandemic. Nutrients, 12(9), 2515. https://doi.org/10.3390/nu12092515

Purdam, K., Garratt, E. A., \& Esmail, A. (2016). Hungry? Food Insecurity, Social Stigma and Embarrassment in the UK. Sociology, 50(6), 1072-1088. https://doi.org/10.1177/0038038515594092

Regan, E. P. (2020). Food insecurity among college students. Sociology Compass, 14(6), 1. https://doi.org/10.1111/soc4.12790

Silva, M. R., Kleinert, W. L., Sheppard, A. V., Cantrell, K. A., Freeman-Coppadge, D. J., Tsoy, E., ... Pearrow, M. (2015). The Relationship Between Food Security, Housing Stability, and School Performance Among College Students in an Urban University. Journal of College Student Retention: Research, Theory \& Practice, 19(3), 284-299. https://doi.org/10.1177/1521025115621918

USDA ERS - Measurement. (2020). Retrieved from https://www.ers.usda.gov/topics/foodnutrition-assistance/food-security-in-the-us/measurement.aspx\#insecurity.

Waity, J. F., Huelskamp, A., \& Russell, J. (2020). Collaborating to Assess and Address Food Insecurity on a College Campus: a Case Study at a Mid-Sized, Regional University. Innovative Higher Education, 45(5), 405-417. https://doi.org/10.1007/s10755-02009512-y

Weaver, R. R., Vaughn, N. A., Hendricks, S. P., McPherson-Myers, P. E., Jia, Q., Willis, S. L., \& Rescigno, K. P. (2019). University student food insecurity and academic performance. Journal of American College Health, 68(7), 727-733. https://doi.org/10.1080/07448481.2019.1600522

Whatnall, M. C., Hutchesson, M. J., \& Patterson, A. J. (2019). Predictors of Food Insecurity among Australian University Students: A Cross-Sectional Study. International Journal of Environmental Research and Public Health, 17(1), 60. https://doi.org/10.3390/ijerph17010060 
INTERNATIONAL JOURNAL OF ACADEMIC RESEARCH IN BUSINESS AND SOCIAL SCIENCES

Vol. 11, No. 6, 2021, E-ISSN: 2222-6990 @ 2021 HRMARS

Xu, X., Zhu, X., \& Bresnahan, M. (2016). Fighting Back. American Behavioral Scientist, 60(11), 1306-1321. https://doi.org/10.1177/0002764216657380 